\title{
Embracing Strategies for eHealth
}

\author{
Lincoln de Assis Moura Jr., President of IMIA \\ Director, AM eHealth - Porto Alegre, RS, Brazil
}

While the first wave of initiatives for the creation of National eHealth policies, strategies, and architectures was to a great extent led by First World countries [1, 2, 3] around 2010, organizations such as ISO, ITU, PAHO, and the WHO embraced the endeavor of developing tools that would help governments, researchers, and Health and Biomedical Informatics practitioners understand the power of eHealth Strategies. Countries were encouraged to direct efforts towards creating a consistent eHealth Vision that is congruent with a country's (or Region's) needs and resources, monitoring and evaluating its implementation, and addressing risk assessment and mitigation. Such tools include a WHO resolution [4], the WHOITU National eHealth Strategy Toolkit [5], PAHO's initiatives and resolutions [6], and a two-part ISO TC 215 technical reference [7].

These initiatives were sown on very fertile ground. Several countries, including low- and middle-income countries (LMICs), have since toiled on the development of their eHealth strategies. A quick, non-exhaustive, Internet search on "eHealth Strategies" shows that countries as varied as Argentina, Brazil, Ghana, Iran, Ireland, Kenya, the Philippines, Qatar, Saudi Arabia, South Africa, Switzerland, Tanzania, and Zimbabwe have recently engaged in developing and deploying their eHealth strategies and architectures, although it is still too early for a broader and deeper assessment of accomplishments . As one would expect, pioneering countries such as Australia, Canada, England, Scotland, Sweden, and the US, to name but a few, have by now reviewed and revised their eHealth Strategies, based on lessons learned from their own experience as well as that of others.

The most important contribution of the organized approach to an eHealth Strategy is that it has taken away the focus from "pure" Health and Biomedical Informatics and makes us consider the whole environment of which eHealth is part of. The WHO/ITU National eHealth Strategy Toolkit [5] proposes seven pillars for an eHealth Strategy, defined as Leadership and Governance; Strategy and Investment; Legislation, Policy and Compliance; Services and Applications; Standards and Interoperability; Infrastructure; Workforce.

Although there has been a great deal of discussion in our field regarding the more technical pillars such as interoperability, capacity building, and even usability, still very little academic research has been published regarding how aspects such as legislation, compliance and leadership impact the conception, design and deployment of eHealth systems and solutions [8].

Given the complexity of Health Information Systems, it is important that our community recognizes the role of the seven pillars even when developing apparently simple and localized eHealth projects. We have learned that, when successful, simple and stand-alone health information systems tend to grow and become more widely adopted. On the other hand, if their foundations are not robust, they are likely to become siloed-systems that fragment the information, the health care processes, and the health care organization itself.

A study on the value of innovation [9] suggests that innovation in strategies though much less usual than innovation in products, processes, and services - creates up to ten times as much value over time.

IMIA has been looking at innovative ways of increasing our reach and being more meaningful to our members and to the World. Serving as a connector and forum of organizations around the globe, IMIA has contributed substantially to the innovation process worldwide. Creating a space for leaders from around the globe to gather and learn, exchange and share through MedInfo is just one of IMIA's contributions. Further, switching the IMIA Yearbook of Health Informatics to free and open access to accelerate sharing was another such initiative and its success is discussed in the proper section of this year's edition.

IMIA is poised and ready to take on the charge of speeding up the development of eHealth strategies around the world. These are exciting times to serve as your president.

http://dx.doi.org/10.15265/IY-2015-024

\section{References}

1. European Commission. eHealth is Worth it. The economic benefits of implemented eHealth solutions at ten European sites. Authors: Karl A. Stroetmann, Tom Jones, Alexander Dobrev, Veli N. Stroetmann. Luxembourg: Office for Official Publications of the European Communities; 2006. ISBN 92-79-02762-X

2. Council of Australian Governments (COAG). Heads of Agreement - National Health Reform. Available at: http://www.coag.gov.au/coag_meeting_outcomes/2011-02-13/docs/communique_attachment_20110213.pdf

3. Canada Health Infoway Annual Report 2008/2009, Building a Healthy Legacy Together. Available at https://www2.infoway-inforoute.ca/Documents/ ar/Annual_Report_2008-2009_en.pdf

4. WHO - WHA Resolution. Resolution A66.24 on eHealth Standardization and Interoperability. http://apps.who.int/gb/ebwha/, 2013.

5. WHO-ITU National eHealth Toolkit, http:// www.who.int/ehealth/publications/overview. pdf?ua $=1 \& u a=1,2012$.

6. PAHO/WHO CD-51 Strategy and Plan of Action on eHealth, http://iris.paho.org/xmlui/handle/123456789/1721, 2011

7. ISO TR 14.639-1:2012 Capacity-based eHealth Architecture Roadmap; 2012.

8. de Assis Moura Jr. L. The Other Side(s) of Health Informatics. Yearb Med Inform 2014:1-2. http:// www.schattauer.de/t3page/1214.html?manuscript $=22290 \& \mathrm{~L}=1$

9. Keeley L. Doblin Inc IBF. Venturing \& Partnering, February 2011. http://corporateventuringconference.com/2012/PRESENTATIONS/2011/04LarryKeeley.pdf 